\begin{tabular}{|c|c|c|c|}
\hline NATAL & $\begin{array}{l}8^{\text {th }} \text { CIDI } \\
8^{\text {th }} \text { Information Design } \\
\text { International Conference }\end{array}$ & $\begin{array}{l}8^{\text {th }} \text { CONGIC } \\
8^{\text {th }} \text { Information Design } \\
\text { Student Conference }\end{array}$ & $\begin{array}{l}\text { Blucher Design Proceedings } \\
\text { Junho } 2018 \text {, num. } 1 \text {, vol. } 4 \\
\text { proceedings.blucher.com.br }\end{array}$ \\
\hline
\end{tabular}

\title{
Entre o design gráfico e a arquitetura: a identidade visual da Fundação Louis Vuitton sob um olhar transcriativo Between graphic design and architecture: Louis Vuitton Foundations' visual identity under a transcreative approach
}

\author{
Laila Rotter Schmidt ${ }^{1}$ - Centro Universitário FAG
}

arquitetura contemporânea; identidade visual; design de sinalização; transcriação; Frank O. Gehry.

Este trabalho realiza uma leitura comparativa entre a arquitetura da sede da Fundação Louis Vuitton, projetada por Frank O. Gehry, a sinalização deste edifício, criada pela agência Zélé-Téra, e a identidade visual desta instituição, desenvolvida pelo studio Base. Tomando como ponto de partida a dimensão de linguagem visual que ambas as disciplinas partilham, busca-se investigar como a sinalização e a identidade visual expressam os mesmos conceitos preconizados na arquitetura do edifício-sede, valendose, no entanto, de estratégias formais específicas. Para dar suporte conceitual à análise, utiliza-se o viés da 'transposição intersemiótica' preconizado por Roman Jakobson e da 'transcriação' de Haroldo de Campos. Com isto, almeja-se demonstrar a riqueza proveniente do diálogo entre design gráfico com outras formas de expressão visual, indicando caminhos possíveis para uma metodologia de criação que leve em conta a transposição entre diferentes linguagens.

contemporary architecture; visual identity; signage design; transcreation; Frank O. Gehry.

This essay performs a comparative reading between Louis Vuitton Foundation's architecture, designed by Frank O. Gehry, the signage design of the same building, designed by the agency Zélé-Téra, and the visual identity of the institution, developed by Studio Base. Having as starting point the visual language dimension that both disciplines share, the research focuses on investigating how signage design and visual identity express the same concepts used on the building of the Foundation's headquarters, using specific design strategies. To give conceptual support to the analisys, the Roman Jakobson's concept of 'intersemiotic translation' and 'transcreation' by Haroldo de Campos. By doing so, it is intended to show the richness coming from the dialogue between graphic design and other forms of visual expression, indicating possible pathways for a methodology of creation that would take into consideration the transposition of different languages.

\section{Introdução}

Design gráfico e arquitetura compartilham entre si uma dimensão de comunicação, assim como outras formas de expressão visual, como a pintura, a fotografia, o cinema e a moda. Isto significa dizer que uma instituição pode dizer algo sobre si tanto por meio da arquitetura de sua sede quanto por meio de sua marca.

A identidade visual, em especial suas aplicações no espaço, como o design de sinalização, constitui-se de um campo privilegiado para observar as interseções entre estas duas disciplinas enquanto linguagens. Ao mesmo tempo em que algumas identidades visuais relacionam-se com a arquitetura por meio de representações icônicas, outras buscam expressões que vão além das semelhanças formais, explorando tanto os princípios de comunicação visual que compartilham, quanto as formas de significação que lhes são específicas.

Quando uma instituição constrói para si um edifício icônico, assinado por um arquiteto mundialmente reconhecido, ela busca um elemento marcante e reconhecível para tornar-se signo da sua identidade. O espaço construído torna-se então a principal referência acerca da

\footnotetext{
1 Mestre em Imagem e Som pela UFSCar. Coordenadora e Professora dos cursos de Publicidade e Propaganda e Tecnologia em Design Gráfico do Centro Universitário FAG. E-mail: lailarsc@yahoo.com.br

Anais do8CIDI e 8CONGIC

Guilherme Santa Rosa; Cristina Portugal (orgs.)

Sociedade Brasileira de Design da Informação - SBDI

Natal | Brasil |2017

ISBN 978-85-212-1305-5
} 


\section{CIDI 2017

instituição, e tende a ser utilizada como subsídio para a criação da sua identidade visual, ou seja 'o conjunto de manifestações físicas a partir do qual uma ideia, um serviço, um produto, uma empresa ou qualquer tipo de associação se apresenta e se faz reconhecer junto a se público' (COELHO, 2011: 205).

Neste contexto, uma abordagem muito comum adotada por profissionais de design gráfico é a representação icônica da arquitetura na assinatura visual e no sistema de identidade institucional. A opção por explorar relações de semelhança formal entre o edifício e a marca da instituição reforça o espaço construído como principal signo representativo da sua identidade.

Dentre os inúmeros exemplos que poderiam ser citados neste contexto, estão o Restaurante The Magazine, em Londres, com arquitetura de Zaha Hadid e identidade visual da Pentagram, e o Palácio do Itamaraty, em Brasília, assinado por Oscar Niemeyer, cuja assinatura visual foi originalmente concebida por Aloísio Magalhães.

Figura 1: Edifício do Restaurante The Magazine Fonte: http://www.magazine-restaurant.co.uk/

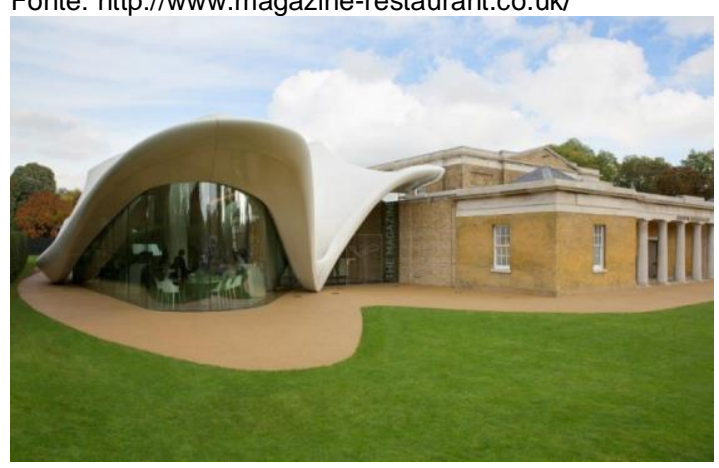

Figura 2: Assinatura Visual do Restaurante The Magazine Fonte: http://www.pentagram.com/\#/projects/114123

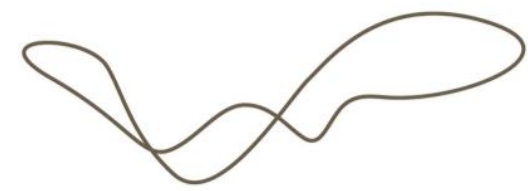

THE MAGAZINE RESTAURANT

Nesta estratégia composicional, os valores da instituição são traduzidos pelo arquiteto na forma de espaço, enquanto cabe ao designer representar graficamente a arquitetura no contexto institucional. Este tipo de identidade visual, por se basear principalmente na representação icônica, tende a gerar uma assinatura cuja leitura é bastante direta e praticamente universal, pois se baseia na aparência do edifício. A opção mais comum é eleger a fachada como elemento de referência, representando-a com maior ou menor grau de abstração.

Figura 3: Palácio do Itamaraty

Fonte: http://www.itamaraty.gov.br/

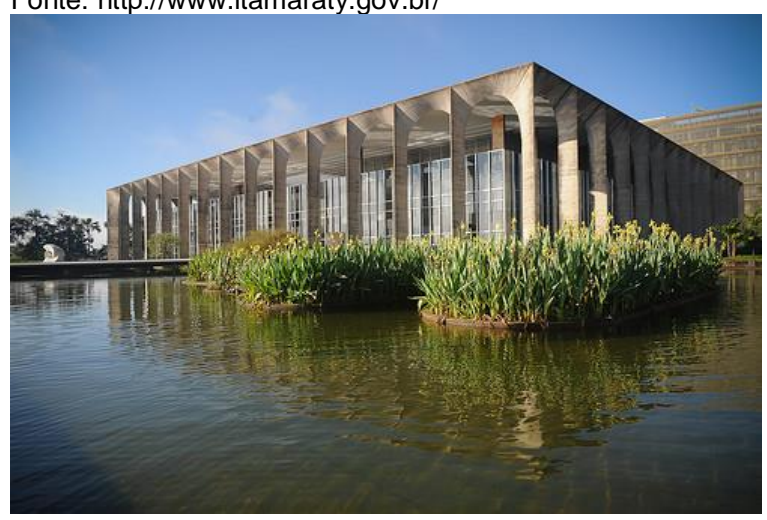

Figura 4: Assinatura Visual do Palácio do Itamaraty Fonte: http://blog.itamaraty.gov.br/

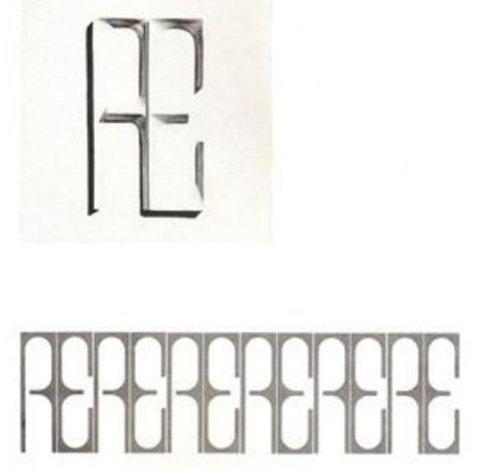

No entanto, basear-se puramente na aparência de um edifício não é a única estratégia possível para referenciá-la em uma identidade visual. Dentre as marcas que exploram uma representação não-icônica da arquitetura, se destacam aquelas que são capazes de traduzir 


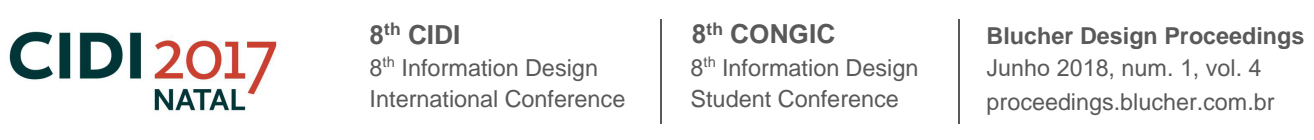

graficamente os mesmos conceitos que fundamentam esteticamente o projeto arquitetônico, utilizando formas que na aparência são totalmente diferentes.

Neste viés, um exemplo notável é a identidade visual da Fundação Louis Vuitton. A Louis Vuitton é uma marca de bolsas e malas de alto padrão e mundialmente conhecida que integra o grupo LVMH - Moët Hennessy Louis Vuitton, o maior conglomerado de produtos de luxo do mundo. Em 2006, o grupo criou a Fundação Louis Vuitton, uma iniciativa cultural privada cujo objetivo é promover e incentivar a criação artística para um público francês e também internacional. A iniciativa de criar a fundação foi de seu presidente Bernard Arnault, que convidou o arquiteto vencedor do Pritzker e mundialmente reconhecido Frank Owen Gehry para projetar o edifício-sede da fundação, a ser instalado em meio ao Jardin D 'Acclimatation em Paris, França, em terreno cedido pelo governo Francês (LA FONDATION, 2017).

A identidade visual da Instituição, que engloba a assinatura visual e materiais institucionais, foi criada pelo studio de branding Base. A proposta gráfica está profundamente enraizada na arquitetura de Gehry, ainda que não utilize nenhum traço formal da fachada. O design de sinalização do edifício, criada pelas agências francesas Zélé e Téra-création, também relaciona-se de forma conceitual com a arquitetura e com a identidade visual, apesar de utilizar elementos gráficos bastante particulares na sua composição.

Figura 5: Fachada da Fundação Louis Vuitton

Fonte: <http://www.fondationlouisvuitton.fr>

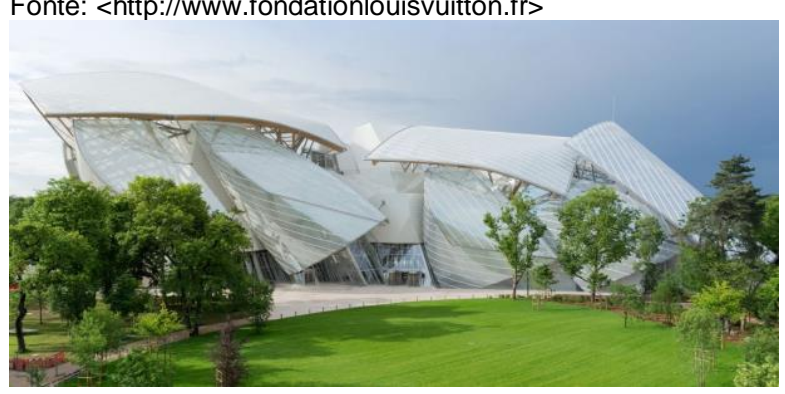

Figura 6: Assinatura Visual

Fonte: <http://www.fondationlouisvuitton.fr>

\section{WOROATON LOUSE VUMTON}

Assim, nos parece possível observar a arquitetura, a identidade visual e a sinalização da Fundação Louis Vuitton como partes de um sistema, no qual os conceitos comunicados são comuns, enquanto as formas de expressão são singulares.

Para estabelecer relações entre os três elementos deste sistema, tomamos arquitetura e design gráfico em sua dimensão de comunicação. Um designer gráfico tem a comunicação como sua principal função, enquanto o propósito fundamental de um arquiteto é projetar espaços que protejam o ser humano do meio ambiente. No entanto, ambos se expressam por meio de uma linguagem visual.

Apesar da sua dimensão funcional, a arquitetura pode ser considerada 'uma forma genérica de expressão que efetivamente informa o homem (e com a qual os homens se informam, de modo consciente ou não)' (COELHO NETTO, 2002: 15). Seja de forma intencional, com um objetivo definido, ou por acaso, como um subproduto da funcionalidade, algum tipo de informação está sempre presente (DONDIS, 1997: 184).

Alguns elementos básicos são comuns a todas as formas de expressão visual. Este vocabulário compartilhado compõe a 'sintaxe da linguagem visual' (DONDIS, 1997: 23), da qual fazem parte elementos como cor e textura, que integram tanto composições espaciais quanto layouts impressos em papel. Para Dondis, é possível atingir o 'alfabetismo visual', que seria a capacidade de ver e compartilhar o significado das mensagens visuais de forma mais ou menos universal (1997: 228). Por outro lado, cada meio de comunicação visual 'tem não apenas seus próprios elementos estruturais, mas também uma metodologia única para a aplicação das decisões compositivas e a utilização de técnicas em sua conceituação e formulação' (DONDIS, 1997: 189). 
Se tomarmos arquitetura e design como duas formas de comunicação visual, que partilham um vocabulário em comum mas que possuem elementos estruturais próprios, nos parece possível observá-los como sistemas de signos diferentes e observar casos como o da Fundação Louis Vuitton sob o ponto de vista de uma 'transposição intersemiótica', conforme estabelecido por Roman Jakobson (1977), o qual se aproxima do que Haroldo de Campos define como 'transcriação' (1987).

Jakobson, ao discutir aspectos linguísticos da tradução, defende que a poesia, é, por definição, intraduzível, sendo possível, apenas sua 'transposição criativa'. No mesmo sentido, é possível encontrar nas pesquisas de Haroldo de Campos a proposição de que o termo 'tradução' não é adequado para tratar da poesia. Campos parte dos postulados de Albercht Fabri e Max Bense, de que a informação estética é inseparável da sua realização.

Assim, a partir da noção de que forma e conteúdo são indissociáveis nos objetos artísticos, presente também nos estudos de Jakobson sobre a função poética, Haroldo define o termo 'transcrição'. 'Para nós, a tradução de textos criativos será sempre recriação, ou criação paralela e autônoma, porém recíproca'. (CAMPOS, 2004: 35) Para ele, o ato transcriativo deve transcender a fidelidade ao conteúdo para conquistar a lealdade ao 'espírito' da obra, ao próprio signo estético como entidade total, indivisa. (CAMPOS, 1987; 2004)

À medida que distancia o ato transcriativo da tradução, Haroldo o aproxima da crítica e da criação. Na visão do autor, transcriar é 'desmontar e remontar a máquina criativa' da obra, exigindo vivência de seu mundo e técnica, mas podendo acrescentar novos estratos criativos que o original permita em sua linha de invenção. (CAMPOS, 1987; 2004)

Nesta direção, a proposta deste trabalho é analisar as relações entre a arquitetura, a identidade visual e o design de sinalização da sede da Fundação Louis Vuitton, desmontando e remontando cada um dos projetos em busca dos elementos de linguagem visual que lhes são comuns e das formas de expressão que Ihes são específicas. Com isto, almeja-se apontar interseções entre a linguagem da arquitetura e do design gráfico, tendo em vista as contribuições que esta observação pode oferecer para a elaboração de uma metodologia de trabalho interdisciplinar no design.

\section{Frank O. Gehry e o edifício da Fundação Louis Vuitton}

Canadense naturalizado norte-americano, Gehry tornou-se um arquiteto mundialmente influente e controverso na década de 80 (MONEO, 2004: 254). Em 1989 conquistou o mais importante prêmio da arquitetura, o Pritzker. O júri considerou seu trabalho 'altamente refinado e sofisticado, com uma estética corajosa que enfatiza a arte da arquitetura' e seus edifícios 'uma expressão única da sociedade contemporânea e seus valores ambivalentes' (FRANK GEHRY..., 1989, tradução nossa).

Gehry integrou a exposição 'Arquitetura Desconstrutivista' organizada por Philip Johnson em 1988 no MoMA - Museu de Arte Moderna de Nova lorque, na qual figuraram também arquitetos como Daniel Libeskind, Rem Koolhaas, Peter Eisenman e Zaha Hadid. A exposição evidenciava 'os contrastes entre as imagens 'deformadas' da arquitetura desconstrutivista e as imagens 'puras' do velho Estilo Internacional.' (JOHNSON, 1988: 7, tradução nossa). Apesar de afirmar que a exposição não possuía a ambição de lançar um novo estilo, Johnson (1988: 7) acabou por criar uma denominação que seria amplamente utilizada para descrever os trabalhos destes arquitetos.

A obra possivelmente mais conhecida de Gehry é o Museu Guggenheim em Bilbao (1997), Espanha. Destacaram-se também o Museu do Design Vitra (1989) em Weil-am-Rhein, Alemanha, e o Teatro Walt Disney (1991) em Los Angeles, Estados Unidos, entre outros. 

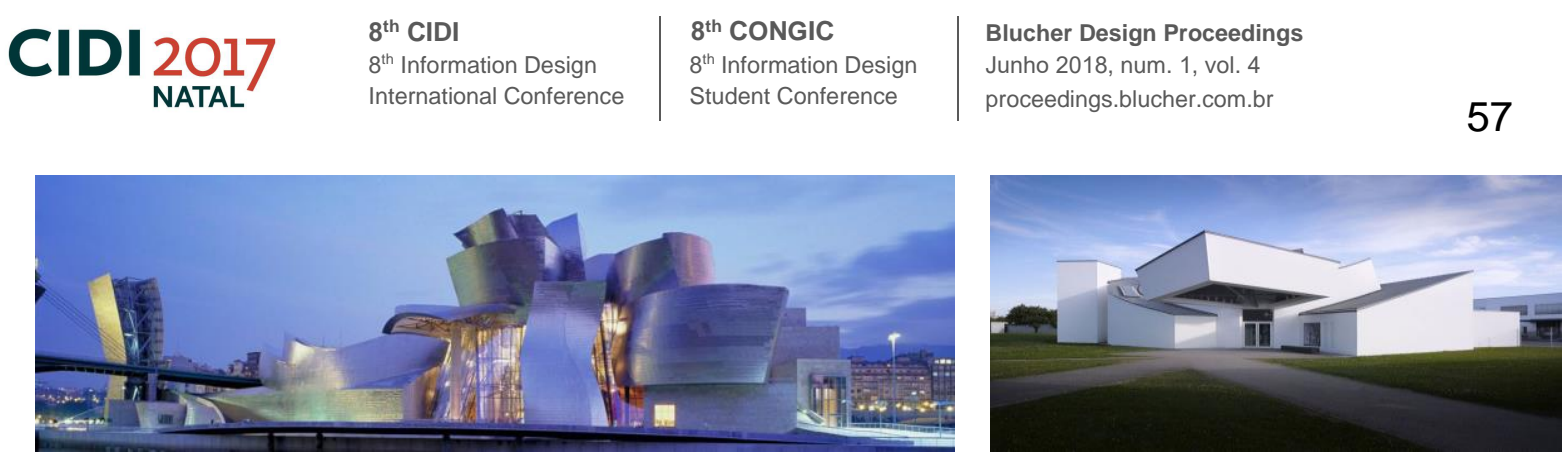

Atualmente, com 87 anos, Gehry continua a provocar o discurso da arquitetura com projetos cada vez mais ousados e controversos (EM FOCO: FRANK..., 2017). Entre seus trabalhos mais recentes está a Fundação Louis Vuitton.

Seguindo uma qualidade marcante dos projetos de Gehry, o edifício da fundação é composto por um conjunto de formas que mesclam características orgânicas e geométricas aglutinadas entre si. 'Gehry geralmente começa por desmembrar o programa. Uma casa é desmontada, e usos são identificados com formas. Sala, cozinha, quarto, escritório, etc. são associados com cubos, cilindros, pirâmides, hemisférios, etc.' (MONEO, 2004: 258).

No entanto, destaca-se em relação a outros projetos, que o material dominante não é o aço (que também está presente, mas em menor destaque) mas sim o vidro, que contribui para que, apesar da complexidade formal do edifício, este pareça muito mais leve e elegante que seus projetos anteriores. O uso do vidro no Edifício da Fundação Louis Vuitton fundamenta-se em dois conceitos básicos: o conceito de uma embarcação à vela; e a tradição dos edifícios de vidro dos jardins do século XIX - que promoviam extensa interação entre o ambiente construído e a vegetação circundante (FUNDAÇÃO LOUIS..., 2014).

A relação com o veleiro é um tema recorrente nos projetos de Gehry, em especial na Neuer Zollhof Düsseldorf, na Alemanha. Em entrevista a Alejandro Zaera-Polo em 1995 para a revista El Croquis, ao ser questionado sobre as formas curvas deste projeto, Gehry respondeu:

São velas; eu sou um marinheiro. Eu tenho um barco, sabia? Adoro velejar e gosto daquelas pinturas holandesas com veleiros, quadros do século XVI, você já viu? Quando você veleja, e quer mudar a rota, a vela está içada, e você a vira lentamente para a outra direção. Há um momento em que você está exatamente na linha do vento e ele vem igualmente pelos dois lados da vela. No segundo antes de pegar o vento na outra direção, ocorre uma pequena ondulação na vela, e ela se dobra... é muito bonito, você tem a sensação do movimento do barco nessa ondulação. (GEHRY, 2015: 232)

$\mathrm{Na}$ Fundação Louis Vuitton, as placas de vidro que lembram as velas de um barco estão fixadas em uma estrutura que mescla aço e madeira, materiais estes também inspirados nos veleiros. As velas são elementos que se sobrepõem a blocos revestidos de concreto branco reforçado com fibras (Ductal), chamados pelo arquiteto de 'icebergs'. A relação com o edifício e um veleiro se torna ainda mais evidente com o fato de ele ser todo cercado por água, que também é um elemento que expressa o caráter de efemeridade e relação com o entorno (FUNDAÇÃO LOUIS..., 2014). A este respeito, Gehry defende que: 'para refletir nosso mundo em mudança constante, queríamos criar um edifício que evoluiria de acordo com o tempo e com a luz para dar a impressão de algo efêmero e em mudança contínua' (L'ÉDIFICE, 2014, tradução nossa).

Figura 9: Fachada da Fundação Louis Vuitton Fonte: <http://www.fondationlouisvuitton.fr>
Figura 10: Detalhe das estruturas de vidro da Fundação Louis Vuitton Fonte: <http://www.fondationlouisvuitton.fr> 

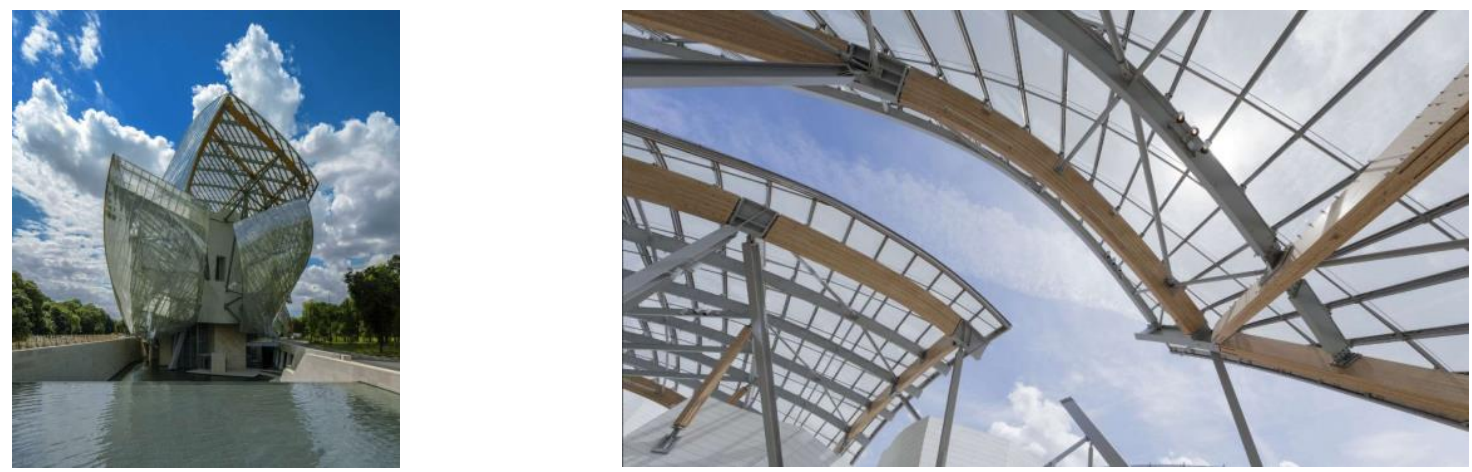

De acordo com Bernard Arnault, a Fundação deveria ser 'um novo espaço para abrir o dialogo com um público mais amplo e oferecer a artistas e intelectuais uma plataforma de debate e reflexão'. No projeto arquitetônico, Gehry elege o veleiro como conceito para expressar a abertura mencionada por Arnault, e daí decorrem as características visuais mais marcantes do edifício: Leveza / Flutuação, que evocam refinamento e neutralidade; e Efemeridade / Permeabilidade, que conferem dinamismo e movimento ao projeto.

Será em busca de expressões gráficas destas características que observaremos, a seguir, os projetos de identidade visual e sinalização do edifício. Começaremos pelo design de sinalização, considerando-o um intermediário entre a arquitetura e o design, visto que 'É um aspecto do espaço construído que se estende aos campos arquitetônico e gráfico' (GALINDO, 2012: 7, tradução nossa).

\section{0 design de sinalização do edifício}

A sinalização envolve todas as formas pelas quais as pessoas se orientam em espaços construídos e navegam de um lugar a outro, exibindo a informação visualmente, por meio de tipografia e elementos gráficos, contribuindo para a compreensão da arquitetura, além de comunicar algo sobre a sua identidade. Em um projeto de sinalização, o design torna-se uma ferramenta para enriquecer a experiência das pessoas nos espaços e lugares (GALINDO, 2012: 7).

Trata-se de um projeto de design bastante complexo e que demanda uma sinergia profunda com a arquitetura. Um projeto de sinalização,

'tem um papel importante tanto na experiência de escolher um caminho dentro de um espaço construído quanto no conjunto de elementos gráficos que apoiam tais decisões. Um design de sucesso integra a sociedade ao ofuscar as fronteiras entre diferentes culturas, línguas e idades, resiste ao tempo ao criar placas amigáveis, usar efetivamente gráficos, cores e formas, criar pictogramas criativos e feitos sob medida para guiar os usuários diários de um edifício ou espaço e explorar a sinalização como um ponto onde arquitetura e design gráfico colidem. (GALINDO, 2012: 8, tradução nossa)

A sinalização do edifício da Fundação Louis Vuitton foi criada em conjunto pelas agências francesas Zélé e Téra-création. Os escritórios se apresentam como uma equipe especializada em projetos de comunicação ambiental e respostas inventivas, que têm em comum um método de trabalhos que não vê fronteiras entre design, grafismos, cenografia e espaço (SIGNALÉTIQUE..., 2014, tradução nossa).

Observando a sinalização, a primeira impressão é que ela é neutra, em contraste à arquitetura, que é extravagante. 'Quando os objetos em uma composição não se destacam em relação aos outros eles são neutros, e a composição como um todo pode ser chamada de neutra' (LEBORG, 2015: 68). No entanto, é possível observar relações conceituais profundas e em total harmonia na arquitetura e no design da sinalização. 


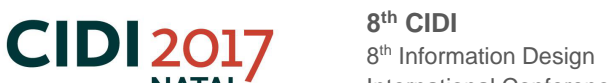

De acordo com o escritório, 'Nossa proposta de sinalização para a Fundação Louis Vuitton acompanha a visita como um sinal discreto' (SIGNALÉTIQUE..., 2014, tradução nossa). Este depoimento deixa transparecer o respeito dos designers com a obra arquitetônica de Gehry, bem como indica que esta foi utilizada como referência para a criação.

A sinalização interna se apresenta predominantemente sobre placas de de Corian@ branco de diversos tamanhos, material que também é utilizado em outras partes do edifício (SIGNALÉTIQUE..., 2014). Os suportes possuem textura lisa e uniforme, e praticamente se fundem com as paredes internas. O conteúdo está aplicado sobre as placas em alto relevo, na cor preta.

Figura 11: 'Informar com discrição' Fonte: <http://www. zele-tera.com>

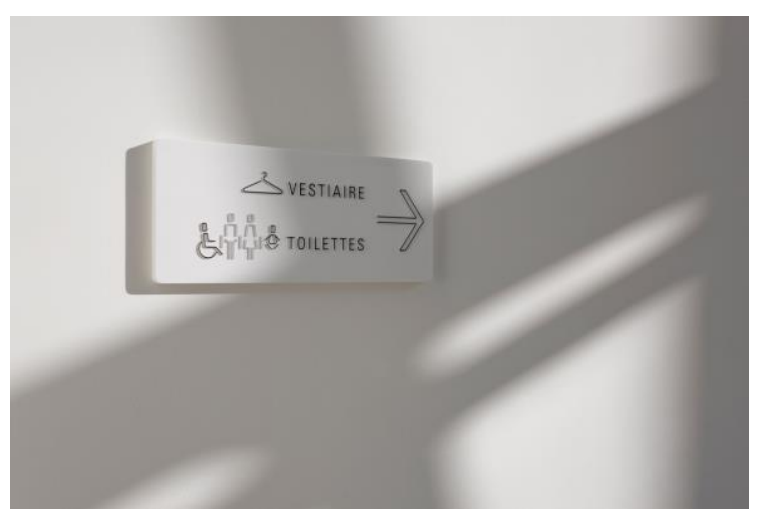

Figura 12: 'Identificação das galerias' Fonte: <http://www. zele-tera.com>

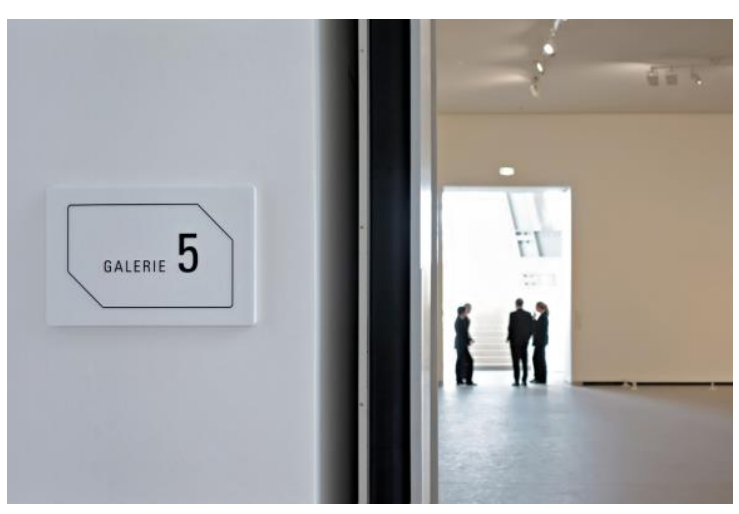

Já a sinalização externa utiliza como suporte o próprio revestimento das paredes do edifício, as placas cimentícias Ductal@ . Neste caso, a delimitação entre o que é sinalização e o que é arquitetura se dissolve ainda mais, já que o conteúdo é aplicado em alto relevo, também na cor preta, sem a delimitação de um suporte, como nas placas internas.

As formas utilizadas nos suportes segue uma lógica ortogonal. 'As formas simples dos suportes com dimensões precisas jogam ortogonalidade na composição, oferecendo calma e conforto de leitura aos visitantes, preservando a 'extravagância' de arquitetura' (SIGNALÉTIQUE..., 2014, tradução nossa). 'Sistemas de símbolos são geralmente baseados em módulos geométricos que se reúnem para criar uma miríade de formas e funções' (LUPTON, 2014: 168).

Figura 13: 'Jogar o jogo do material' Fonte: <http://www.zele-tera.com>

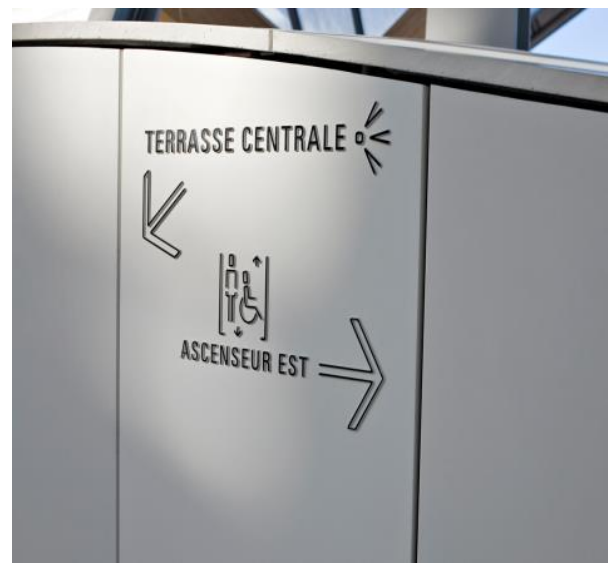

Figura 14: 'Estar em simbiose' Fonte: <http://www.zele-tera.com>

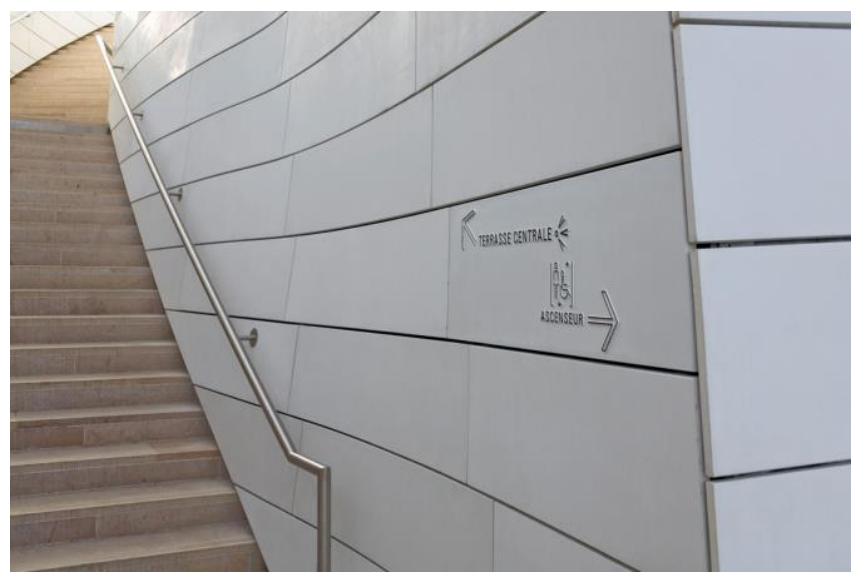




\section{CIDI 2017

A sinalização da fachada e da setorização interna do edifício possuem uma estrutura um pouco diferente, mas que conceitualmente se relaciona com o restante do projeto de sinalização. No caso da identificação das divisões internas, a mesma tipografia utilizada nas placas é aplicada em backlight branco, diretamente sobre a estrutura arquitetônica, sem um suporte específico. Algumas aplicações complementares são feitas com adesivo aplicado diretamente sobre o vidro, sobre o piso ou outros suportes como faixas delimitadoras do espaço, sempre em preto ou branco, dependendo do tom que melhor contrasta com a superfície em que estão aplicados. Estão sempre integrados com a paisagem arquitetônica.

Figura 17: 'Identificar as divisões internas' Fonte: <http://www.zele-tera.com>

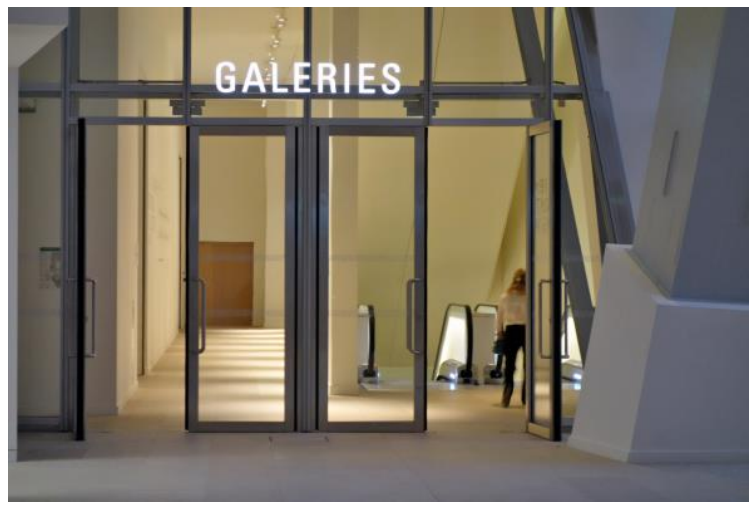

Figura 18: 'Acompanhar as ações' Fonte: <http://www.zele-tera.com>

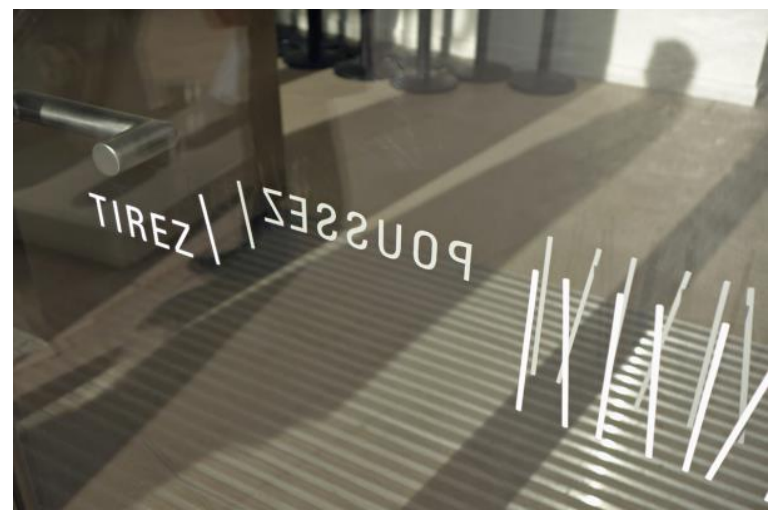

Em todos os casos, o plano que dá suporte à sinalização não é evidente. Um plano, em comunicação visual, é uma superfície contínua que se estende em altura e largura, e que possui contorno e preenchimento (LUPTON, 2014: 18). Sua principal característica é o senso de massa, e, por consequência, de peso visual (SAMARA, 2007: 53). A parede do edifício é um plano, e o suporte que acomoda o conteúdo, outro plano que se coloca sobre este. $O$ fato de ambos possuírem preenchimento e textura semelhantes faz com que o contorno seja perceptível apenas com a ação da luz, que revela a tridimensionalidade do suporte sobre a parede. Em suma, a superfície está em total simbiose com o espaço construído e a sensação de massa praticamente inexiste.

A luz, assim, cumpre um papel importante na percepção da sinalização, visto que evidencia tanto o alto relevo dos suportes internos em relação às paredes, quanto o conteúdo em relação aos suportes e paredes do edifício. Nesta direção, o escritório afirma que: 'O conceito oferece um design à flor da pele, com ressonância de branco sobre branco em um jogo de contrastes, sombras e luzes, sensível ao toque'. (SIGNALÉTIQUE..., 2014, tradução nossa)

O conjunto iconográfico criado para o projeto vale-se de 'uma linguagem gráfica tipo 'emoticon', universal e lúdica, que combina pictogramas com palavras, como um rébus' (SIGNALÉTIQUE..., 2014, tradução nossa). É interessante observar como, em meio a uma maioria de signos iconográficos, aquele escolhido para representar os terraços vale-se de um símbolo amplamente utilizado em projetos arquitetônicos para representar uma vista.

Figura 15: 'Vocabulário de identidade' Fonte: <http://www. zele-tera.com>
Figura 16: 'Palavras-imagem'

Fonte: Idem 

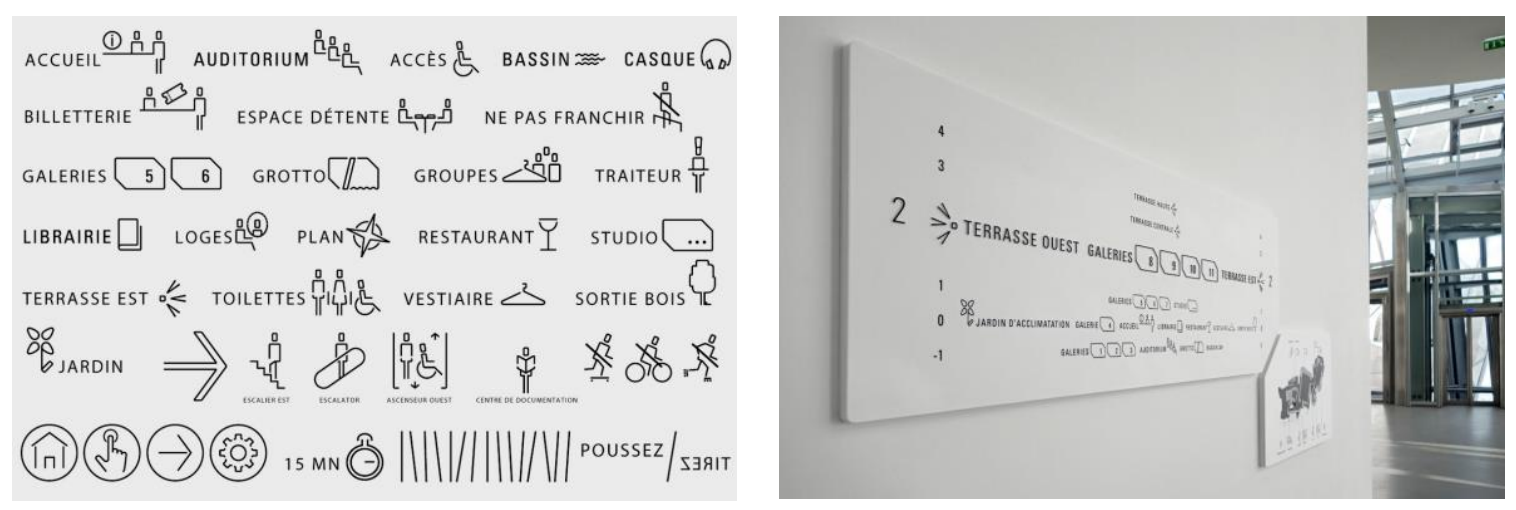

Os pictogramas são formados por linhas finas e delicadas, traçadas na cor preta. Em comunicação visual, linhas são frequentemente utilizadas na condição de contorno, para delimitar planos e descrever formas (DONDIS, 1997: 57). 'Uma linha fecha-se para tornar-se uma forma, um plano delimitado' (LUPTON, 2014: 18).

No entanto, na sinalização criada pela Zélé-Téra as linhas que delimitam os pictogramas nunca se fecham completamente, deixando as formas abertas. Isso evidencia o contorno e não o preenchimento das formas, ou seja, sua característica de linha e não de plano. 'Uma forma com contorno complexo, e uma grande medida de interação entre espaços positivos e negativos, internos e externos, se torna mais fraco, com características de linha, e exibe uma massa mais leve' (SAMARA, 2007: 53).

A exceção são os ícones representativos das galerias, que formam um retângulo totalmente fechado. Seria possível pensar que no edifício o único espaço fechado são as galerias, e por isto sua representação se dá desta forma. Ou ainda, podem ser vistas como delimitações inspiradas em uma planta arquitetônica, assim como a simbologia dos terraços.

O aspecto formal da tipografia está em total harmonia com a linguagem dos ícones. A fonte sem serifa e sem contraste na largura das hastes parece ter sido desenhada com as mesmas linhas que formam os pictogramas. 'A linha é também um instrumento nos sistemas de notação, como por exemplo, a escrita' (DONDIS, 1997: 56). A fonte é leve e condensada, evidenciando mais a verticalidade que a horizontalidade, e totalmente uniforme.

A linha tem por principal característica o movimento, o que faz com que a composição seja extremamente dinâmica. 'Nas artes visuais, a linha tem, por sua própria natureza, uma enorme energia. Nunca é estática; é o elemento visual inquieto e inquiridor do esboço' (DONDIS, 1997: $56)$.

Também contribui para o dinamismo na composição o fato de que o conjunto iconografia e tipografia estão soltos sobre o plano. Seria possível dizer que estão 'flutuando' sobre os suportes, quando estes não são a própria arquitetura.

Em relação ao projeto arquitetônico de Gehry, é possível observar que a sinalização desenvolvida pela Zélé-Téra apresenta os mesmos conceitos anteriormente destacados. Os conceitos de Leveza e Flutuação aparecem de diferentes formas na sinalização. Tanto os suportes quanto os pictogramas e tipografias são extremamente leves, pois o senso de massa dos planos formados é reduzido ao máximo. O conteúdo parece, de fato, flutuar sobre os suportes, que em muitos casos são a própria arquitetura, já que os contornos e a delimitação dos planos é pouco evidente. O resultado é refinado e discreto como quis o escritório que a concebeu.

Já a estreita relação entre a sinalização e a luz, bem como o dinamismo e sentido de movimento que decorre dos altos relevos, pode ser compreendido como uma expressão dos conceitos de Efemeridade e Permeabilidade, tomados da arquitetura. A cada momento do dia, 
conforme a luz muda, também muda a percepção da sinalização. A relação entre arquitetura e sinalização é extremamente permeável, sendo que em alguns momentos as duas chegam a se confundir, ficando os limites entre elas não muito claros.

$\mathrm{Na}$ arquitetura, a transparência do vidro é a principal responsável pela expressão dos conceitos de Leveza e Permeabilidade.

Um objeto transparente é aquele que nos permite ver através dele. A luz brilha através do objeto de modo que outros objetos que estão atrás dele se tornem visíveis. Um objeto opaco é visualmente impermeável e não permite que a luz o atravesse. (LEBORG, 2015: 75)

$\mathrm{Na}$ sinalização, tanto no que se refere ao suporte quanto ao seu conteúdo, as estratégias adotadas pelos designers evocam constantemente o conceito de transparência, apesar de não o utilizarem no sentido estrito da palavra. 'A transparência pode servir para enfatizar valores de honestidade e clareza através de ajustes e justaposições que mantém a integridade ou legibilidade dos elementos' (LUPTON, 2014: 147).

No design gráfico, a transparência é sempre uma simulação do que no plano real é uma característica de translucidez inerente ao material. 'Os designers podem traduzir os efeitos de transparência física em camadas sobrepostas de linhas, formas, texturas ou letras. Chamamos este fenômeno de 'transparência gráfica". (LUPTON, 2014: 150)

No caso da sinalização da Fundação Louis Vuitton, não há simulação de transparência, pois os elementos são todos opacos. Porém, há a sugestão desta, ao se dissolver os contornos dos suportes, assim como ao evidenciar as linhas que contornam as formas e não o seu preenchimento. 'Uma superfície construída a partir de elementos completamente opacos pode funcionar de maneira transparente' (LUPTON, 2014: 147)

Assim como quis Campos, a sinalização da Fundação Louis Vuitton transcende a fidelidade ao conteúdo para conquistar a lealdade ao 'espírito' da obra, ao próprio signo estético como entidade total, indivisa, (CAMPOS, 1987; 2004) nos parecendo ser possível observar este processo como um ato transcriativo.

\section{A identidade visual da Fundação Louis Vuitton}

Identidade Visual é um termo utilizado, em design, para se referir ao conjunto de elementos gráficos que representam visualmente a personalidade de uma instituição. 'Esses elementos agem mais ou menos como as roupas e as formas de as pessoas se comportarem. Devem informar, substancialmente, à primeira vista' (STRUNK, 2003: 57).

Um sistema de identidade visual abrange tanto a assinatura visual quando um conjunto de materiais institucionais, que devem representar os conceitos da marca de forma coesa. 'Um programa de identidade de marca abrange uma linguagem visual excepcional e única que se expressa em todas as aplicações' (WHEELER, 2012: 152).

A assinatura e identidade visual da Fundação Louis Vuitton foi criada pelo studio de branding Base, que possui escritórios em Bruxelas, Nova lorque e Genebra. De acordo com o diretor de design, Sander Vermeulen,

Bernard Arnault ofereceu a Paris um novo e excepcional espaço para a arte contemporânea. Frank Gehry criou um edifício emblemático, uma 'embarcação de vidro simbolizando a chamada cultural da França'. Nossa tarefa era criar a logomarca e linguagem visual que respeitasse a visão dos dois mestres do projeto (A NEW PRESENT..., 2004, tradução nossa).

A fala de Vermeulen indica que a obra de Gehry foi tomada como referência para a identidade visual, o que é reforçado na fala de Lara Berg, designer do Base: 'Não queríamos competir com a criação de Gehry. Ela é icônica em si mesma. Ao invés de criar uma assinatura 
para, ou tradução gráfica do edifício, gostaríamos de criar algo que refletisse os ideais e motivos por trás dele' (A NEW PRESENT..., 2004, tradução nossa).

O studio partiu do conceito de embarcação à vela, porém, conferiu-lhe um recorte específico. De acordo com Thierry Brunfaut, diretor criativo do Base, 'Quando você está no mar olhando para o horizonte, ele parece não ter fim. Nós queríamos captar esse sentimento de 'horizontes sem fim', e a ideia de territórios distantes que ainda serão descobertos' (A NEW PRESENT..., 2004).

A assinatura visual é tipográfica, ou seja, composta unicamente pela escrita 'Fundação Louis Vuitton' aplicada em uma fonte sem serifa, regular e de peso médio. Uma textura em gradação, formada pela repetição de pequenos pontos quadrangulares, com maior densidade na parte inferior e menor densidade na parte superior, dá impressão de a tipografia estar se desmaterializando, de baixo para cima, expressando, assim, o conceito de 'horizonte distante' mencionado pela equipe do Base.

Através do uso consciente da parte superior e inferior de uma formato, o designer pode brincar com associações a respeito de como experimentamos o mundo, aludindo à terra e ao céu. A composição pode criar a ilusão de algo leve ou pesado, ou algo que voa, ou de algo que flutua (LEBORG, 2015: $65)$.

Não existe contorno traçado na identidade visual. Este é apenas sugerido pela textura que evidencia sua superfície. A gradação gera transparência e evoca movimento, na medida em que uma base sólida e opaca se torna, gradativamente, uma superfície vazada e permeável. ' $O$ movimento é um tipo de mudança, e toda mudança acontece no tempo' (LUPTON, 2014: 215).

A assinatura visual apresenta-se em uma única cor, geralmente preto ou branco, e também em três cores: preto, cinza e verde, representando o edifício e o parque. A relação figura e fundo é reversível, ou seja, apresenta 'elementos positivos e negativos atraem nossa atenção igualmente e alternadamente, avançando e depois recuando, à medida que nossos olhos os percebem como dominantes e, em seguida, subordinados' (LUPTON, 2014: 86).

Figura 17: Assinatura Visual

Fonte: <https://basedesign.com>

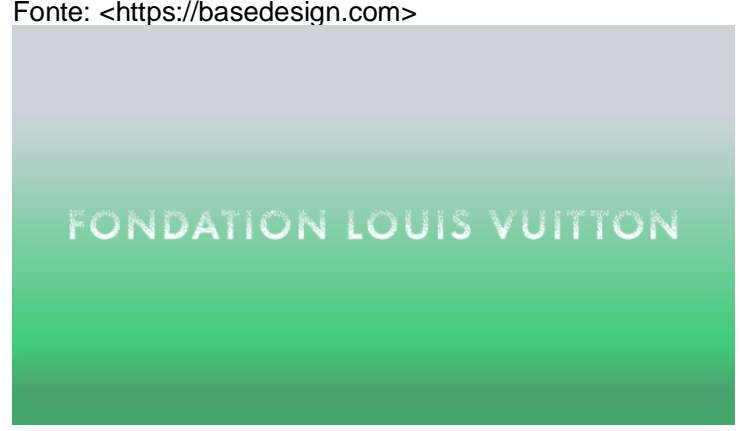

Figura 18: Detalhe da assinatura visual Fonte: fotografia do original feita pelo o autor (mai/2016)

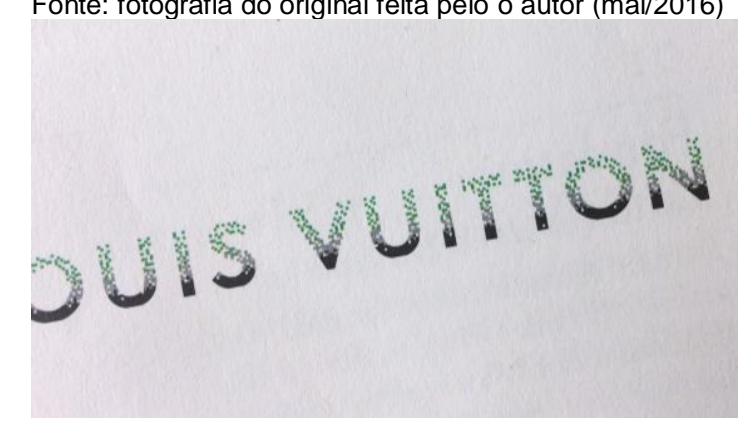

Do sistema de identidade visual, destacam-se aqui dois materiais em específico: o cartão de visita e o mapa de boas-vindas. No cartão de visita, a mesma textura gradiente utilizada na assinatura visual é reproduzida na base do cartão, em hotstamping na cor prateada sobre fundo branco. O uso deste acabamento gera um efeito reflexivo, que permite que o material interaja com a luz, mudando sua percepção conforme a condição luminosa.

No mapa de boas-vindas, observa-se o uso das três cores institucionais em uma diagramação rigorosa e com amplas áreas de respiro e predominância do branco. São utilizados neste material, elementos pictográficos da sinalização criada pela Zélé-Téra. É interessante observar como o sistema pictográfico parece muito diferente no material impresso em relação à sinalização do edifício, o que demonstra como a tridimensionalidade e a relação com a luz são aspectos determinantes da proposta. 
Figura 19: Aplicação em cartão de visita Fonte: <https://basedesign.com>

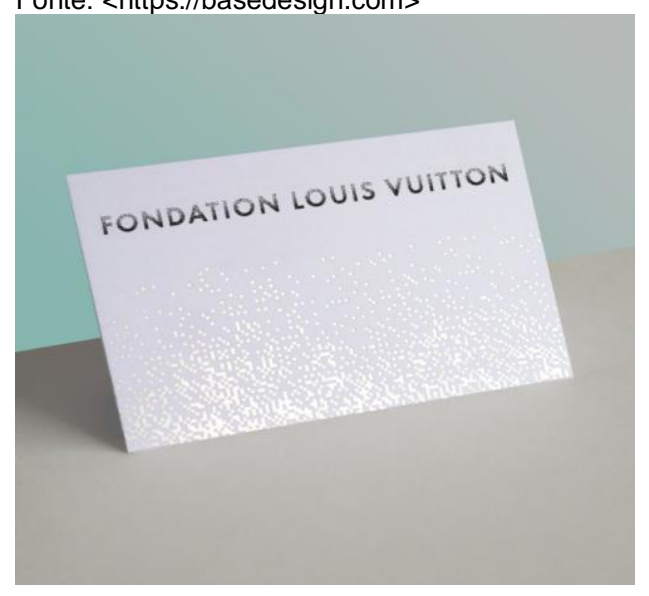

Figura 20: Mapa do edifício da Fundação Louis Vuitton Fonte: fotografia do original feita pelo o autor (mai/2016)

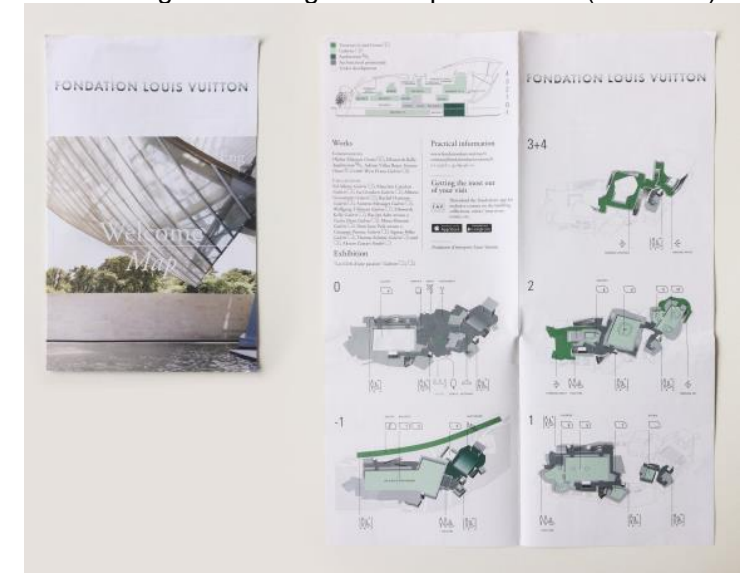

Partindo os conceitos já apresentados de Leveza e Efemeridade, é possível relacionar a identidade visual da Fundação Louis Vuitton tanto com a arquitetura de Gehry quanto com a sinalização da Zélé-Téra, reforçando a ideia de uma transcriação entre diferentes linguagens visuais.

A transparência está presente na textura em gradação aplicada tanto na assinatura quanto em outros materiais de identidade visual, conferindo tanto leveza quanto permeabilidade à composição. A impressão visual que os elementos menos densos da parte superior evocam é precisamente de flutuação.

Assim como a sinalização, a identidade visual também evoca o tátil ao criar uma textura, 'elemento visual que com frequência serve de substituto para as qualidades de outro sentido, 0 tato’ (DONDIS, 1997: 70).

O contraste entre o sólido e o permeável, positivo e negativo, contida na própria composição da assinatura visual pode ser relacionado com o contraste que se estabelece entre o vidro translúcido das velas e a solidez e opacidade dos 'icebergs' na obra de Gehry. 'Os termos negativo e positivo referem-se a valores opostos, como opaco e transparente, claro e escuro, convexo e côncavo, sólido e oco' (LEBORG, 2015: 74).

$\mathrm{Na}$ composição dos materiais institucionais, as amplas áreas de respiro das composições reforçam o caráter de leveza e permeabilidade do material. A permeabilidade se apresenta também no uso de hotstamp, que estabelece, assim como a sinalização, uma relação de mudança conforme a luz incidente sobre o material.

As cores escolhidas relacionam-se tanto com o edifício (branco, preto e cinza) quanto com o parque (verde). $\mathrm{Na}$ identidade visual as cores se misturam, reforçando o caráter de permeabilidade entre os diferentes elementos.

\section{Conclusão}

A partir destas observações, parece possível afirmar que a sinalização e a identidade visual da Fundação Louis Vuitton se relacionam profundamente com o edifício projetado por Frank Gehry. Esta relação não se estabelece em um nível icônico, de reprodução formal dos elementos visuais reconhecíveis (forma, material, estrutura), mas a um nível conceitual, que assume diferentes formas de acordo com a especificidade do meio pelo qual se expressa. 


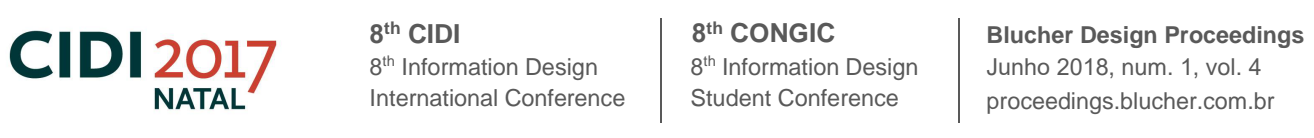

Um efeito em especial é explorado de formas completamente diferentes, mas é facilmente reconhecível nos três projetos: a transparência. Ela é a chave para a expressão dos conceitos de Leveza / Flutuação e Efemeridade / Permeabilidade em todos os três projetos.

Diferentemente da sinalização, que enfatizou a ausência de preenchimento, retirando o foco da superfície e evidenciando os contornos, a identidade propõe o oposto: evidenciar o preenchimento, e com ele, a superfície, em um elemento sem contorno.

$\mathrm{Na}$ arquitetura e na sinalização, observamos as linhas como elementos proeminentes na composição, evocando dinamismo de forma muito natural. Já na identidade visual, são predominantes os pontos, que, em conjunto, geram uma textura e superfície evidente. Ao contrário do edifício, que abusa das formas orgânicas e irregulares, a sinalização e a identidade visual assumem formas geométricas e ortogonais.

Na sinalização, os contornos sem preenchimento são explorados para tornar a composição leve e permeável, enquanto na identidade o preenchimento sem contorno é explorado para gerar o mesmo efeito de flutuação e efemeridade. Enquanto o projeto de sinalização é agudo com linhas definidas, cores sólidas e contrastes brutos, a identidade visual é difusa - com mudanças sutis e graduais entre cores e densidades.

Assim, acreditamos que a identidade visual e a sinalização da Fundação Louis Vuitton podem ser tomadas como 'transcriações' ou 'transposições intersemióticas' do edifício de Frank Gehry, no sentido em que transcende a fidelidade ao significado para conquistar uma lealdade ao 'espírito do original transladado' e à sua carga conceitual (CAMPOS, 2004: 47).

\section{Referências}

50 ANOS DO PALÁCIO ITAMARATY. Ministério das relações exteriores. In: $<$ http://www.itamaraty.gov.br/pt-BR/component/content/article?id=15823:50-anos-do-palacioitamaraty>, 18/06/2017

A FLOATING VESSEL. Sander Vermeulen Portfolio. In: http://www.iamsanderson.com/fondation-louis-vuitton/, 12/05/2017

A NEW PRESENT FOR PARIS: An exploding ship full of art. Base Design. In: https://basedesign.com/case-study/base-brands-fondation-louis-vuitton/, 12/05/2017

CAMPOS, Haroldo de. 1987. Da transcriação: poética e semiótica da operação tradutora. In: OLIVEIRA, Ana Cláudia de; SANTAELLA, Lucia. Semiótica da literatura. São Paulo: Educ, 1987. Cadernos PUC, n. 28.

CAMPOS, Haroldo de. 2004. Metalinguagem e outras metas. 4. ed. São Paulo: Perspectiva.

COELHO NETO, J. Teixeira. 2002. A construção do sentido na arquitetura. 5. ed. São Paulo: Perspectiva. 2011.

COELHO, Luiz Antonio L. (org). Conceitos-chave em design. Rio de Janeiro: PUC-Rio,

DONDIS, Donis A. 1997. Sintaxe da linguagem visual. São Paulo: Martins Fontes.

EM FOCO: FRANK GEHRY. ArchDaily. In: http://www.archdaily.com.br/br/01-179571/felizaniversario-frank-gehry, 12/05/2017

FRANK GEHRY 1989 LAUREATE. The Pritzker Architecture Prize. In: http://www.pritzkerprize.com/1989, 12/05/2017

FUNDAÇÃO LOUIS VUITTON GEHRY PARTNERS. ArchDaily. In: http://www.archdaily.com.br/br/755262/fundacao-louis-vuitton-gehry-partners, 12/05/2017

GALINDO, Michelle. 2012. Signage Design. Berlin: Braun.. 
JAKOBSON, Roman. 1977. Lingüística e comunicação. Tradução de Izidoro Blikstein e José Paulo Paes. 9. ed. São Paulo: Cultrix. York.

JOHNSON, Philip. 1988. Deconstructivist architecture. The Museum of Modern Art: New

LA FONDATION. Fondation Louis Vuitton. In: http://www.fondationlouisvuitton.fr/en/lafondation.html, 12/05/2017

LEBORG, Christian. 2015. Gramática visual. São Paulo: Gustavo Gili.

L'ÉDIFICE. Fondation Louis Vuitton. In: http://www.fondationlouisvuitton.fr/l-edifice.html, $12 / 05 / 2017$

LUPTON, Ellen. 2014. Novos fundamentos do design. São Paulo: Cosac Naify.

MONEO, Rafael. 2004. Theoretical anxiety and design strategies in the work of eight contemporary architects. Spain: The MIT Press.

SAMARA, Timothy. 2007. Design elements: a graphic style manual. Beverly: Rockport Publishers.

SIGNALÉTIQUE FONDATION LOUIS VUITTON. Téra-création \& Zélé, In: http://zeletera.com, 12/05/2017

STRUNK, Gilberto. 2003. Como criar identidades visuais para marcas de sucesso: um guia sobre o marketing das marcas e como representar graficamente seus valores. Rio de Janeiro: Rio Books.

WHEELER, Alina. 2012. Design de Identidade de Marca: guia essencial para toda a equipe de gestão de marcas. Porto Alegre: Bookman.

WONG, Wucius. 1998. Princípios de forma e desenho. São Paulo: Martins Fontes.

ZAERA-POLO, Alejandro. 2015. Arquitetura em diálogo. São Paulo: Cosac Naify. 